\title{
ESTUDO CINÉTICO DO CRESCIMENTO DO CLOSTRIDIUM ACETOBUTYLICUM ATCC 4259 UTILIZANDO GLICEROL P.A. COMO SUBSTRATO
}

\author{
C. E. de O. LACERDA ${ }^{1}$, G. M. VINHAS ${ }^{1}$, Y. M. B. de ALMEIDA ${ }^{1}$ \\ ${ }^{1}$ Universidade Federal de Pernambuco, Departamento de Engenharia Química \\ E-mail para contato: carlos.olacerda@hotmail.com
}

\begin{abstract}
RESUMO - A glicerina, subproduto da produção de biodiesel, vem sendo investigada como fonte de carbono em processos microbianos para a obtenção de bioprodutos com alto valor agregado. A avaliação do crescimento do microorganismo responsável por essa bioconversão é uma importante etapa desse processo. O presente trabalho consistiu em avaliar a cinética de crescimento do Clostridium acetobutylicum ATCC 4259 através de uma fermentação em batelada utilizando glicerol P.A. como fonte de carbono. A técnica de peso seco foi utilizada para o calculo da concentração do micro-organismo presente no meio de cultura após a fermentação. A cinética microbiana mostrou que, para as condições experimentais da pesquisa, a fase exponencial de crescimento ocorreu até o tempo de 14 horas, e uma produtividade celular (P) de 0,0405 g/L.h, uma velocidade máxima de crescimento $\left(\mu_{\text {máx }}\right)$ de $0,0403 \mathrm{~h}^{-1}$ e um tempo de geração $(\mathrm{G})$ de $15,7 \mathrm{~h}$ foram alcançados.
\end{abstract}

\section{INTRODUÇÃO}

O biodiesel é um combustível renovável, biodegradável e não tóxico. Pode ser definido como sendo um mono-alquil éster de ácidos graxos derivados de fontes renováveis (óleos vegetais e gordura animal) com álcool na presença de um catalisador, obtido através de um processo de transesterificação, no qual ocorre a transformação de triglicerídeos em moléculas menores de ésteres de ácidos graxos e tendo como subproduto principal, a glicerina (glicerol mais impurezas) (Fukuda et al., 2009; Leoneti et al., 2012).

Nos primeiros anos de produção do biodiesel, a alta percentagem de glicerina obtida era considerada como um aspecto positivo, e com sua venda, o aumento da competitividade econômica global da fabricação de biodiesel parecia seguro, uma vez que a glicerina gerada na produção corresponde a aproximadamente $10 \%$ do volume total de biodiesel produzido (Yazdani \& Gonzalez, 2007). Em 2010, a produção de biodiesel no Brasil foi de aproximadamente 2,4 bilhões de litros, o que gerou aproximadamente 240 milhões de litros de glicerina (Leoneti et al., 2012).

O acúmulo da oferta ocasionado pelo crescimento das indústrias de biocombustíveis e a quantidade de impurezas encontradas na glicerina bruta, fizeram com que seu preço diminuísse com o passar dos anos (Yazdani \& Gonzalez, 2007; Asad-Ur-Rehman et al., 2008). Desta forma, essa glicerina oriunda da produção de biodiesel passou de um produto apreciado a um problema de eliminação de resíduo, e existe um grande interesse em sua 
purificação ou no seu reaproveitamento direto sem tratamento, proporcionando ao processo de produção de biodiesel maior competitividade e valorização crescente no mercado de biocombustíveis (Kaur et al., 2012; Clomburg et al., 2013).

Sendo assim, a glicerina bruta não purificada ou com purificação parcial vem sendo investigada como fonte de carbono em processos microbianos para obtenção de bioprodutos de alto valor agregado como 1,3-propanodiol, etanol, butanol, acetona, ácido acético, ácido butírico, ácido cítrico, ácido fórmico, ácido lático, ácido succínico, $\mathrm{CO}_{2} \mathrm{e} \mathrm{H}_{2}$. (Anand et al., 2011; Clomburg et al., 2013).

O estudo cinético do crescimento do micro-organismo responsável por essa bioconversão é uma importante etapa para compreender todo o mecanismo e otimizar o processo de fermentação. (Sun et al., 2008). A formação de biomassa no processo fermentativo depende de duas moléculas transportadoras de energia, o $\mathrm{NAD}^{+}$(dinucleotídeo de adenina nicotinamida) e o ATP (adenosina trifosfato) (Kaur et al., 2012).

O crescimento de um micro-organismo está dividido em quatro fases: a fase lag, conhecida também como fase de adaptação, em que nenhum crescimento aparente ocorre, uma vez que as células estão se adaptando ao meio de cultivo; tem-se a fase exponencial, também conhecida como fase logarítmica ou fase log, em que ocorre um aumento exponencial do número de células, atingindo a sua velocidade máxima; a fase estacionária, onde a população atinge seu máximo e constante crescimento; e a fase da morte, onde, devido ao acúmulo de metabólitos e limitação de nutrientes, eventualmente poderá ocorrer um declínio do número de células, característico dessa fase (Bastos, 2010).

O objetivo do presente trabalho foi avaliar a cinética de crescimento do Clostridium acetobutylicum ATCC 4259 através de uma fermentação em batelada utilizando glicerol P.A. como fonte de carbono.

\section{MATERIAIS E MÉTODOS}

\subsection{Materiais}

Micro-organismo: O micro-organismo utilizado no trabalho foi o Clostridium acetobutylicum ATCC 4259. Essa linhagem foi cedida pela coleção de micro-organismos UFPEDA do Departamento de Antibióticos da UFPE. Foi adquirida em tubos contendo meio RCM (Caldo Clostridial Reforçado) semissólido, e foi mantida em estufa a $37^{\circ} \mathrm{C}$ até ser inoculada e/ou repicada.

Soluções Utilizadas: Meio de tioglicolato fluido (marca DIFCO), utilizado para manutenção e crescimento do micro-organismo e solução salina para diluição (Tabela 1). 
Tabela 1 - Composição da solução salina para diluição

\begin{tabular}{cc}
\hline \multicolumn{2}{c}{ Solução A } \\
\hline $\mathrm{KH}_{2} \mathrm{PO}_{4}$ & $34,0 \mathrm{~g}$ \\
Água destilada & $1000,0 \mathrm{~mL}$ \\
\hline \multicolumn{2}{c}{ Solução B } \\
\hline $\mathrm{MgSO}_{4} \cdot 7 \mathrm{H}_{2} \mathrm{O}$ & $50,0 \mathrm{~g}$ \\
Água destilada & $1000,0 \mathrm{~mL}$ \\
\hline \multicolumn{2}{c}{ Solução Salina } \\
\hline Solução A & $1,25 \mathrm{~mL}$ \\
Solução B & $5,0 \mathrm{~mL}$ \\
Água destilada & $1000,0 \mathrm{~mL}$ \\
\hline
\end{tabular}

A pré-cultura utilizada para adaptar o micro-organismo aos componentes do meio de cultura para fermentação tem a seguinte composição (Günzel et al., 1991): $\mathrm{K}_{2} \mathrm{HPO}_{4}(3,4 \mathrm{~g} / \mathrm{L}$ ), $\mathrm{KH}_{2} \mathrm{PO}_{4}(1,3 \mathrm{~g} / \mathrm{L}),\left(\mathrm{NH}_{4}\right)_{2} \mathrm{SO}_{4}(2,0 \mathrm{~g} / \mathrm{L}), \mathrm{MgSO}_{4} \cdot 7 \mathrm{H}_{2} \mathrm{O}(0,2 \mathrm{~g} / \mathrm{L}), \mathrm{CaCl}_{2} \cdot 2 \mathrm{H}_{2} \mathrm{O}(0,02 \mathrm{~g} / \mathrm{L})$, $\mathrm{CaCO}_{3}(2,0 \mathrm{~g} / \mathrm{L})$, extrato de levedura $(1,0 \mathrm{~g} / \mathrm{L})$, glicerol P.A. (20 g/L), solução de elementos traços $(1,0 \mathrm{~mL} / \mathrm{L})($ Tabela 2$)$ e solução de ferro $(2,0 \mathrm{~mL} / \mathrm{L})($ Tabela 3$)$.

Tabela 2 - Composição da solução de elementos traços

\begin{tabular}{cc}
\hline \multicolumn{3}{c}{ Componentes } \\
\hline $\mathrm{ZnCl}_{2}$ & $0,070 \mathrm{~g} / \mathrm{L}$ \\
$\mathrm{MnCl}_{2} \cdot 4 \mathrm{H}_{2} \mathrm{O}$ & $0,100 \mathrm{~g} / \mathrm{L}$ \\
$\mathrm{H}_{3} \mathrm{BO}_{3}$ & $0,060 \mathrm{~g} / \mathrm{L}$ \\
$\mathrm{CoCl}_{2} \cdot 6 \mathrm{H}_{2} \mathrm{O}$ & $0,200 \mathrm{~g} / \mathrm{L}$ \\
$\mathrm{CuCl}_{2} \cdot 2 \mathrm{H}_{2} \mathrm{O}$ & $0,020 \mathrm{~g} / \mathrm{L}$ \\
$\mathrm{NiCl}_{2} \cdot 6 \mathrm{H}_{2} \mathrm{O}$ & $0,025 \mathrm{~g} / \mathrm{L}$ \\
$\mathrm{Na}_{2} \mathrm{MoO}_{4} \cdot \mathrm{H}_{2} \mathrm{O}$ & $0,035 \mathrm{~g} / \mathrm{L}$ \\
$\mathrm{HCl} 37 \%$ & $0,900 \mathrm{~mL} / \mathrm{L}$ \\
\hline
\end{tabular}

Tabela 3 - Composição da solução de Ferro

\begin{tabular}{cc}
\hline \multicolumn{2}{c}{ Componentes } \\
\hline $\mathrm{FeSO}_{4} .7 \mathrm{H}_{2} \mathrm{O}$ & $5,0 \mathrm{~g} / \mathrm{L}$ \\
$\mathrm{HCl} 37 \%$ & $4,0 \mathrm{~mL} / \mathrm{L}$ \\
\hline
\end{tabular}


A concentração dos nutrientes do meio de cultura para fermentação é igual à concentração dos nutrientes da pré-cultura, com exceção de: $\mathrm{K}_{2} \mathrm{HPO}_{4}(1,0 \mathrm{~g} / \mathrm{L}), \mathrm{KH}_{2} \mathrm{PO}_{4}(0,5$ $\mathrm{g} / \mathrm{L}),\left(\mathrm{NH}_{4}\right)_{2} \mathrm{SO}_{4}(1,0 \mathrm{~g} / \mathrm{L})$ e solução de ferro $(1,0 \mathrm{~mL} / \mathrm{L})$.

\subsection{Metodologia Experimental}

Preparação dos meios de cultura: Os meios de cultura foram preparados de acordo com as seguintes etapas: os nutrientes de cada meio foram pesados e diluídos em água destilada; após diluição, foram insuflados com gás nitrogênio e aquecidos a $\mathrm{T}=55^{\circ} \mathrm{C}$ durante 20 minutos; os meios de cultura então foram transferidos para tubos de penicilina e para o frasco biorreator, selados e lacrados; seguiram então para a esterilização em autoclave, a $121{ }^{\circ} \mathrm{C}$ por 15 minutos.

Preparo da cinética: Utilizando uma seringa (c/ agulha) estéril, o C. acetobutylicum ATCC 4259 foi inoculado em um tubo de penicilina de $100 \mathrm{~mL}$ contendo $90 \mathrm{~mL}$ de meio de tioglicolato fluido na proporção de $10 \% \mathrm{v} / \mathrm{v}$ e incubado a $35{ }^{\circ} \mathrm{C}$. Após 24 horas de crescimento o micro-organismo foi inoculado, também na proporção de $10 \% \mathrm{v} / \mathrm{v}$, em outro tubo de penicilina de $100 \mathrm{~mL}$ contendo $90 \mathrm{~mL}$ de pré-cultura. Após as 24 horas, o microorganismo adaptado na pré-cultura foi inoculado no meio de fermentação para realização da cinética. A cinética foi conduzida em um frasco biorreator de $500 \mathrm{~mL}$, sem controle de $\mathrm{pH}$, temperatura e agitação, contendo $300 \mathrm{~mL}$ de meio de cultura para fermentação que foi inoculado com $34 \mathrm{~mL}$ de inóculo vindo da pré-cultura (correspondendo a $10 \% \mathrm{v} / \mathrm{v}$ ). O frasco seguiu para a incubadora a $\mathrm{T}=35^{\circ} \mathrm{C}$ durante $20 \mathrm{~h}$, tempo que durou a fermentação.

Avaliação da biomassa: Para avaliar o crescimento do micro-organismo foi utilizada a técnica do peso seco. Em intervalos de 1 hora, amostras de $10 \mathrm{~mL}$ foram retiradas do frasco biorreator e filtradas com o auxílio de um conjunto para filtração em membranas de $2 \mu \mathrm{m}$ previamente taradas, utilizando água de diluição (Tabela 1) para lavagem. Antes de cada filtração, o frasco foi levemente agitado para homogeneizar o meio e a retirada das amostras foi realizada de maneira estéril, com o auxílio da chama do bico de Bunsen As membranas permaneceram 2 horas na estufa a $\mathrm{T}=80{ }^{\circ} \mathrm{C}$ para secar o filtrado. A diferença entre o peso inicial da membrana e o peso após a secagem determina a biomassa que cresceu durante a fermentação.

Cálculo dos parâmetros cinéticos: Para calcular os parâmetros importantes da cinética microbiana, têm-se as Equações 1, 2 e 3. A Equação 1 determina a produtividade celular (P) que é a relação entre a variação da concentração celular pela variação do tempo de cultivo englobando todas as fases de crescimento microbiano (Borzani et al., 2001).

$$
\mathrm{P}=\frac{\left(\mathrm{X}-\mathrm{X}_{0}\right)}{\left(\mathrm{t}-\mathrm{t}_{0}\right)}
$$

A Equação 2 mostra a velocidade máxima de crescimento do micro-organismo $\left(\mu_{\text {máx }}\right)$. $O$ intervalo de tempo $\mathrm{t}_{-} \mathrm{t}_{0}$ corresponde apenas à fase exponencial de crescimento; $\mathrm{X}_{0}$ é a 
concentração celular no início da fase exponencial de crescimento, enquanto $\mathrm{X}$ é a concentração celular no final dessa fase (Bastos, 2010).

$$
\mu_{\text {máx }}=\frac{\ln \left(\mathrm{X} / \mathrm{X}_{0}\right)}{\mathrm{t}-\mathrm{t}_{0}}
$$

A Equação 3 mostra o tempo de geração $(\mathrm{G})$, ou seja, o tempo que o micro-organismo leva para duplicar a sua biomassa. O tempo de geração também é calculado apenas na fase exponencial de crescimento. Esse parâmetro é importante na interpretação do crescimento celular, uma vez que dá uma ideia mais prática de quão rápido ocorre o crescimento do microorganismo (Bastos, 2010).

$$
\mathrm{G}=\frac{\ln 2}{\mu_{\text {máx }}}
$$

\section{RESULTADOS E DISCUSSÃO}

\subsection{Resultados da cinética microbiana}

Os resultados da cinética microbiana encontram-se na Tabela 4.

Tabela 4 - Construção da curva de crescimento por peso seco

\begin{tabular}{cccc}
\hline Tempo (h) & Concentração $(\mathrm{g} / \mathrm{L})$ & Tempo $(\mathrm{h})$ & Concentração $(\mathrm{g} / \mathrm{L})$ \\
\hline 1 & 0,92 & 11 & 1,37 \\
2 & 0,88 & 12 & 0,20 \\
3 & 1,18 & 13 & 1,22 \\
4 & 0,16 & 14 & 1,60 \\
5 & 1,25 & 15 & 1,49 \\
6 & 1,37 & 16 & 1,45 \\
7 & 0,14 & 17 & 1,43 \\
8 & 1,31 & 18 & 1,61 \\
9 & 1,51 & 19 & 1,66 \\
10 & 1,18 & 20 & 1,69 \\
\hline
\end{tabular}

Com os valores encontrados na Tabela 4 , foi calculada a produtividade celular $\mathrm{P}=$ $0,0405 \mathrm{~g} / \mathrm{L}$.h. Esse valor representa diretamente o crescimento celular em $\mathrm{g} / \mathrm{L}$ a cada hora de experimento. Na Figura 1 encontra-se a regressão quadrática do crescimento celular em função do tempo. 


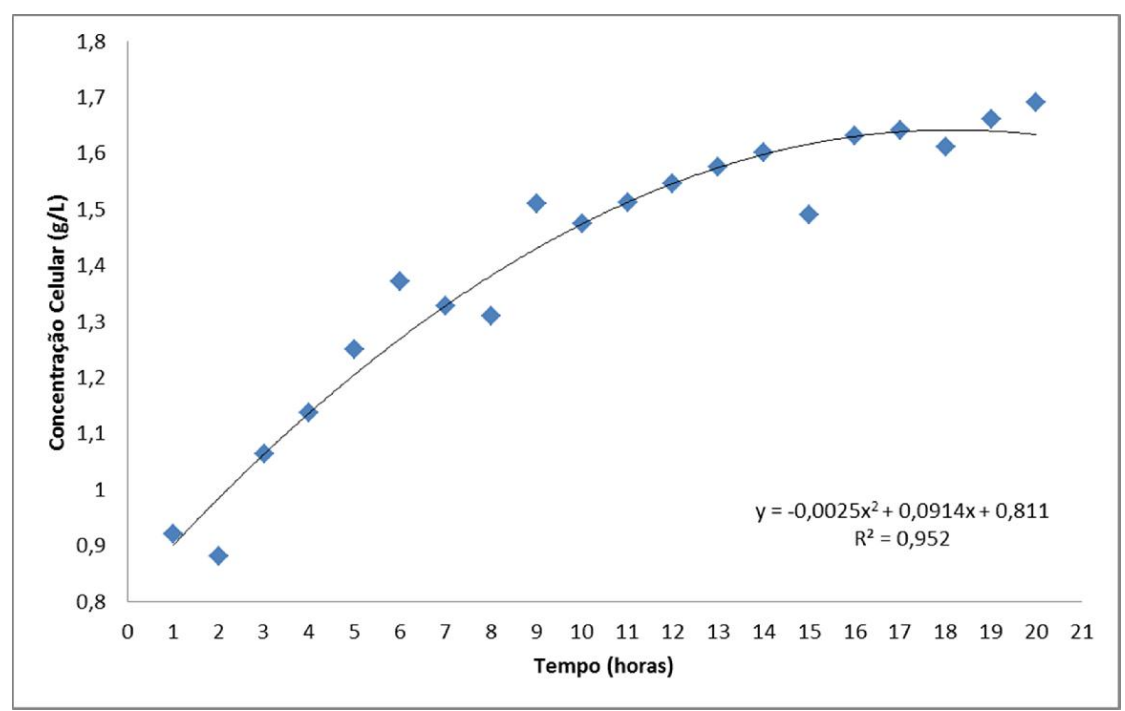

Figura 1 - Crescimento celular ajustado

Incialmente observa-se através da Figura 1 que a fase lag de crescimento não é visualizada, o que mostra que o Clostridium acetobutylicum ATCC 4259 se adaptou bem ao meio de cultura. Pode-se identificar a fase de crescimento exponencial para as nossas condições experimentais. Essa fase exponencial ocorre até o ponto de 14 horas. Além disso, temos a fase estacionária de crescimento a partir de 14 horas.

Podemos encontrar a velocidade máxima de crescimento $\left(\mu_{\text {máx }}\right)$ através da Equação 2, calculando o logaritmo neperiano de $\mathrm{X} / \mathrm{X}_{0}$ e construindo o gráfico da Figura 2. Na Tabela 5 encontram-se os resultados desses cálculos.

Tabela 5 - Valores de $\ln \left(\mathrm{X} / \mathrm{X}_{0}\right)$ para cálculo da velocidade máxima de crescimento

\begin{tabular}{cccccc}
\hline Tempo $(\mathrm{h})$ & $\mathrm{X}(\mathrm{g} / \mathrm{L})$ & $\ln \left(\mathrm{X} / \mathrm{X}_{0}\right)$ & Tempo $(\mathrm{h})$ & $\mathrm{X}(\mathrm{g} / \mathrm{L})$ & $\ln \left(\mathrm{X} / \mathrm{X}_{0}\right)$ \\
\hline 1 & 0,92 & 0 & 8 & 1,31 & 0,353409 \\
2 & 0,88 & $-0,04445$ & 9 & 1,51 & 0,495491 \\
3 & 1,06 & 0,141651 & 10 & 1,47 & 0,468644 \\
4 & 1,14 & 0,21441 & 11 & 1,51 & 0,495491 \\
5 & 1,25 & 0,306525 & 12 & 1,55 & 0,521637 \\
6 & 1,37 & 0,398192 & 13 & 1,57 & 0,534457 \\
7 & 1,33 & 0,368561 & 14 & 1,60 & 0,553385 \\
\hline
\end{tabular}




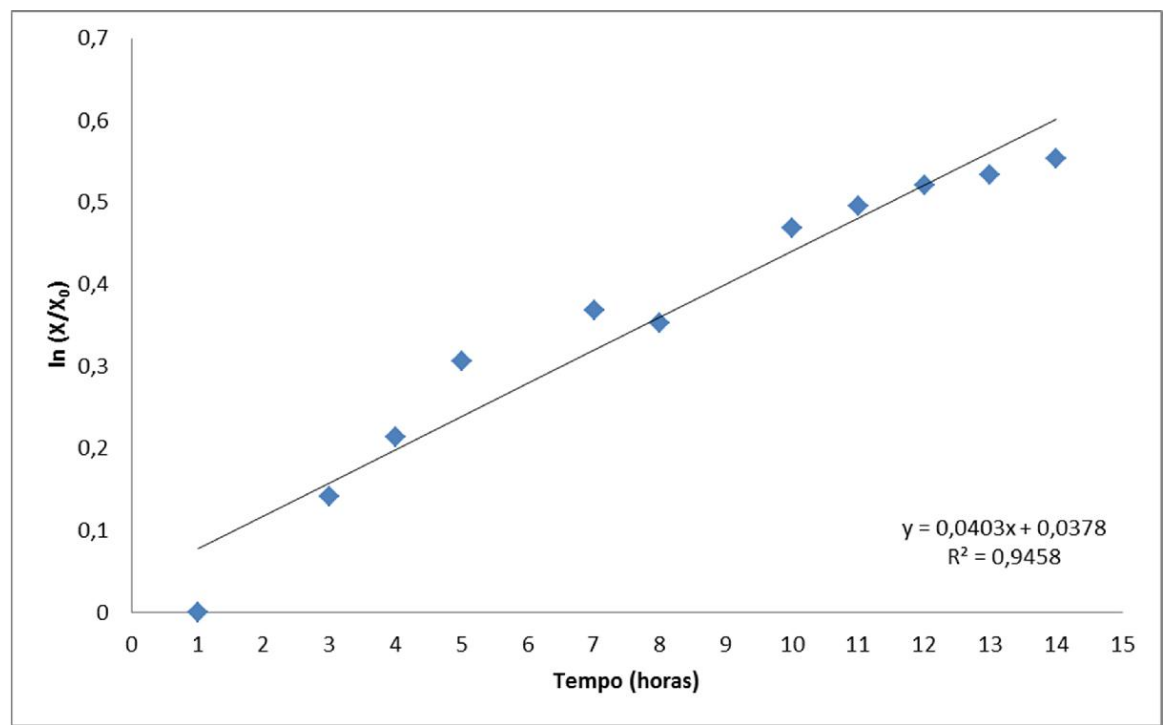

Figura 2 - Caracterização do $\mu_{\text {máx }}$ para o experimento

O coeficiente angular da equação da reta do gráfico da Figura 2 representa a velocidade máxima de crescimento celular, portanto $\mu_{\text {máx }}=0,0403 \mathrm{~h}^{-1}$.

De posse do valor da velocidade máxima, podemos calcular $\mathrm{G}$, o tempo de geração, através da Equação 3. Então, temos que $\mathrm{G}=15,7 \mathrm{~h}$. Esse valor representa o tempo necessário para que o micro-organismo duplique a sua biomassa. Então, quanto menor o valor de $\mathrm{G}$, mais rápido é o crescimento.

\section{CONCLUSÕES}

As condições operacionais para manutenção e crescimento do Clostridium acetobutylicum ATCC 4259 foram alcançadas, produzindo inóculos com boa viabilidade e respostas satisfatórias para o crescimento do micro-organismo utilizando glicerol P.A. como principal fonte de carbono em um processo descontínuo.

Foi possível observar que o Clostridium acetobutylicum ATCC 4259 alcançou o fim da fase exponencial de crescimento em 14 horas de fermentação. Então, estudando apenas essa fase, dados cinéticos que caracterizam o crescimento do micro-organismo foram coletados. Os dados serviram para compreender o seu comportamento diante do meio de cultura próprio para a produção de 1,3-propanodiol.

O primeiro dado importante foi o tempo de geração $(\mathrm{G}=15,7$ horas $)$. Através desse valor conclui-se que o Clostridium acetobutylicum ATCC 4259 leva aproximadamente toda a fase exponencial de crescimento para duplicar a sua biomassa. Fato esse que pôde ser observado também pela baixa velocidade de crescimento máxima $\left(\mu_{\text {máx }}=0,0403 \mathrm{~h}^{-1}\right)$, característica do gênero Clostridium. 


\section{REFERÊNCIAS}

ANAND, P.; SAXENA, R. K.; MARWAH, R. G. A novel downstream process for 1,3propanediol from glycerol-based fermentation. Appl. Microbiol. Biotechnol., v. 90, n. 4, p. 1267-1276, 2011.

ASAD-UR-REHMAN; MATSUMURA, M.; NOMURA, N.; SATO, S. Growth and 1,3propanediol production on pre-treated sunflower oil biodiesel raw glycerol using a strict anaerobe Clostridium butyricum. Curr. Res. Bacteriol., v. 1, n. 1, p. 7-16, 2008.

BASTOS, R. G. Tecnologia das fermentações: fundamentos de bioprocessos. São Carlos: EdUFSCar, 2010.

BORZANI, W.; SCHMIDELL, W.; LIMA, A. U.; AQUARONE, E. Biotecnologia Industrial. Volume 2, São Paulo: Edgar Bülcher, 2001.

CLOMBURG, J. M.; GONZALEZ, R. Anaerobic fermentation of glyrcerol: a plataform for renewable fuels and chemicals. Trends Biotecnol., v. 31, p. 20-28, 2013.

FUKUDA, H.; KONDO, A.; TAMALAMPUDI, S. Bioenergy: sustainable fuels from biomass by yeast and fungal whole-cell biocatalysts. Biochem, Eng. J., v. 44, p. 2-12, 2009.

GÜNZEL B.; YONSEL, S.; DECKWER, W. D. Fermentative production of 1,3-propanediol from glycerol by Clostridium butyricum up to a scale of $2 \mathrm{~m}^{3}$. Appl. Microbiol., v. 36, p. 289-294, 1991.

KAUR, G.; SRIVASTAVA, A. K.; CHAND, S. Advances in biotechnological production of 1,3-propanediol. Biochem. Eng. J., v. 64, p.106-118, 2012.

LEONETI, A. B.; ARAGÃO-LEONETI, V.; DE OLIVEIRA, S. V. W. B. Glycerol as a byproduct of biodiesel production in Brazil: alternatives for the use of unrefined glycerol. Renew. Energ., v. 45, p. 138-145, 2012.

SUN, Q. Y.; QI, T. W.; TENG, H.; XIU, L. Z.; ZENG, P. A. Mathematical modeling of glycerol fermentation by Klebsiella pneumonia: concerning enzyme-catalytic reductive pahway and transport of glycerol and 1,3-propanediol across cell membrane. Biochem. Eng. J., v. 38, p. 22-32, 2008.

YAZDANI, S. S.; GONZALEZ, R. Anaerobic fermentation of glycerol: a path economic viability for the biofuels industry. Curr. Opin. Biotech., v. 18, p. 213-219, 2007. 